\title{
Epigenome-Wide Effects of Vitamin D ${ }^{\dagger}$
}

\section{Carsten Carlberg}

School of Medicine, Institute of Biomedicine, University of Eastern Finland, FI-70211 Kuopio, Finland; carsten.carlberg@uef.fi

+ Presented at Natural Products and the Hallmarks of Chronic Diseases-COST Action 16112, Luxemburg, 25-27 March 2019.

Published: 17 April 2019

\begin{abstract}
Vitamin $\mathrm{D}_{3}$ has, via its metabolite 1,25-dihydroxyvitamin $\mathrm{D}_{3}\left(1,25(\mathrm{OH})_{2} \mathrm{D}_{3}\right)$, a high affinity to the transcription factor vitamin $\mathrm{D}$ receptor (VDR), and thereby directly affects the epigenome of its target tissues. Changing the transcriptome results in modulation of physiological function, such as calcium homeostasis and the response of innate and adaptive immunity. Genome-wide datasets on the 1,25(OH $)_{2} \mathrm{D}_{3}$-triggered binding of VDR, its pioneer factors PU.1 and CEPBA, histone markers and chromatin accessibility in THP- 1 human monocytes compared to those obtained in peripheral blood mononuclear cells from vitamin $\mathrm{D}_{3}$-supplemented human volunteers (VitDbol study) allow the assessment of the epigenome-wide effects of vitamin D.
\end{abstract}

Keywords: vitamin D; epigenomics; gene regulation; VDR; vitamin D intervention studies; chromatin; monocytes

Funding: This article is based upon work from COST Action NutRedOx-CA16112 supported by COST (European Cooperation in Science and Technology).

Conflicts of Interest: The authors declare no conflict of interest.

(C) 2019 by the authors. Licensee MDPI, Basel, Switzerland. This article is an open access article distributed under the terms and conditions of the Creative Commons Attribution (CC BY) license (http://creativecommons.org/licenses/by/4.0/). 